\title{
A rare cutaneous tumor: Dermatofibrosarcoma protuberans
}

\author{
Nuran Alli ${ }^{1,2}$, Ahu Yorulmaz ${ }^{2}$, Huseyin Ustun ${ }^{3}$ \\ ${ }^{1}$ Department of Dermatology, Kafkas University School of Medicine, Kars, Turkey, ${ }^{2}$ Department of Dermatology, Ankara \\ Numune Research and Education Hospital, Ankara, Turkey, ${ }^{3}$ Department of Pathology, Kafkas University School of \\ Medicine, Kars, Turkey
}

Corresponding author: Dr. Ahu Yorulmaz, E-mail: ahuyor@gmail.com

\begin{abstract}
Dermatofibrosarcoma protuberans (DFSP) is a rare indolent cutaneous tumor which has been considered as a low-grade dermal and subcutaneous fibrohistiocytic neoplasm. DFSP expands slowly but recurs frequently leading to the general assumption that DFSP is a locally aggressive neoplasm. This low-grade/borderline tumor which is generally found on trunk and proximal extremities of adults has limited potential for metastasis. Clinical presentation is usually typical with a red-brown or skin coloured indurated plaque with multiple nodules or protuberances. Histopathology of DFSP is also characteristical which demonstrates storiform pattern of uniform spindle cells infiltrating deep into the subcutaneous fat tissue constituting honeycomb appearence. Here, we report a case of DFSP in a 50-year-old woman who presents with a twenty year history of slowly growing mass on her left femoral area.
\end{abstract}

Key words: Dermatofibrosarcoma protuberans; Fibrohistiocytic; Spindle-shaped

\section{INTRODUCTION}

Dermatofibrosarcoma protuberans (DFSP) is a rare low-grade soft tissue sarcoma, which usually tends to be localized though frequently exhibits signs of recurrence. Seldomly metastasizing, its locally aggressive behavior has been attributed to its tendency to multiple recurrences. Although it may arise anywhere on the body, typical site of involvement is the trunk and proximal extremities. DFSP is also an exceptional dermatological disease in that it is associated with a genetic translocation involving chromosomes 11 and $22[\mathrm{t}(17 ; 22)(\mathrm{q} 22 ; \mathrm{q} 13)][1-5]$.

\section{CASE REPORT}

A 50-year-old woman was admitted to our outpatient clinic with a twenty year history of slowly growing mass on her left femoral area. Her past and family history were unremarkable. Upon dermatological examination we observed a peripherally erythematous, centrally violaceous indurated plaque with multiple nodules or protuberances on her left femoral area (Fig. 1). Histopathological examination of lesional skin biopsy demonstrated storiform pattern of uniform spindle cells infiltrating deep into the

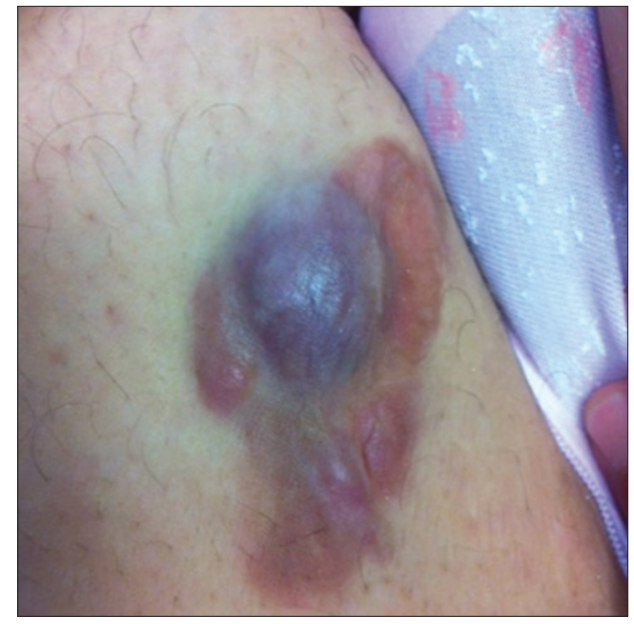

Figure 1: Peripherally erythematous, centrally violaceous indurated plaque with multiple nodules or protuberances on left femoral area.

\footnotetext{
How to cite this article: Alli N, Yorulmaz A, Ustun H. A rare cutaneous tumor: Dermatofibrosarcoma protuberans. Our Dermatol Online. 2017;8(4):446-448. 
subcutaneous fat tissue constituting honeycomb appearance (Figs. 2 and 3). Immunohistochemically tumor cells stained positively for CD34, negatively for CD68 and 5\% positively for Ki67 (Fig. 3). Based on history, clinical and histopathological findings, we made a diagnosis of DFSP and the patient was referred to general surgery and medical oncology departments for the complete excision of the tumor and follow-up of the patient.

\section{DISCUSSION}

Dermatofibrosarcoma protuberans (DFSP) is a rare monoclonal mesenchymal sarcoma. It differs from
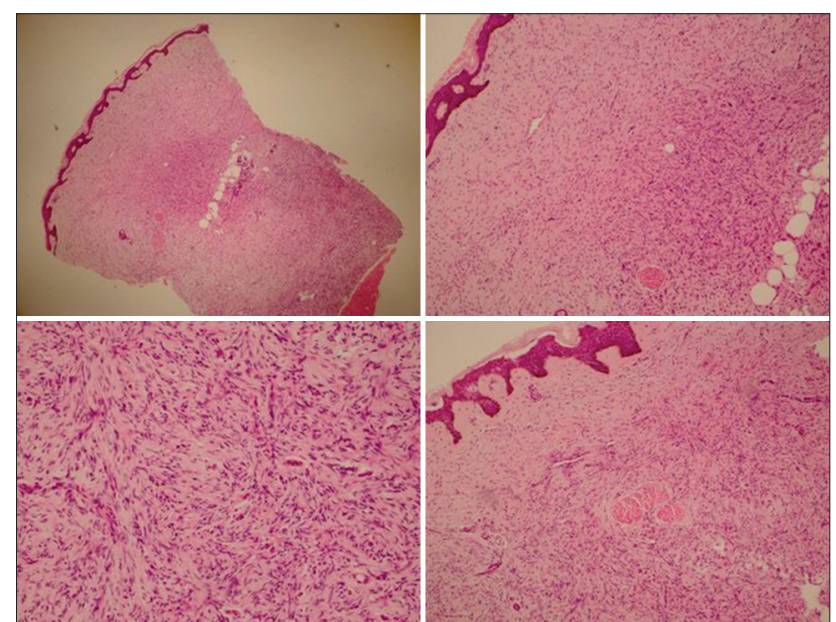

Figure 2: Histopathological features of the neoplasm demonstrating storiform pattern of uniform spindle-shaped cells with eosinophilic cytoplasm and hyperchromatic nuclei infiltrating deep into the subcutaneous fat tissue constituting honeycomb appearance (from left top to right bottom; H\&E x10, x20, x40, x20).

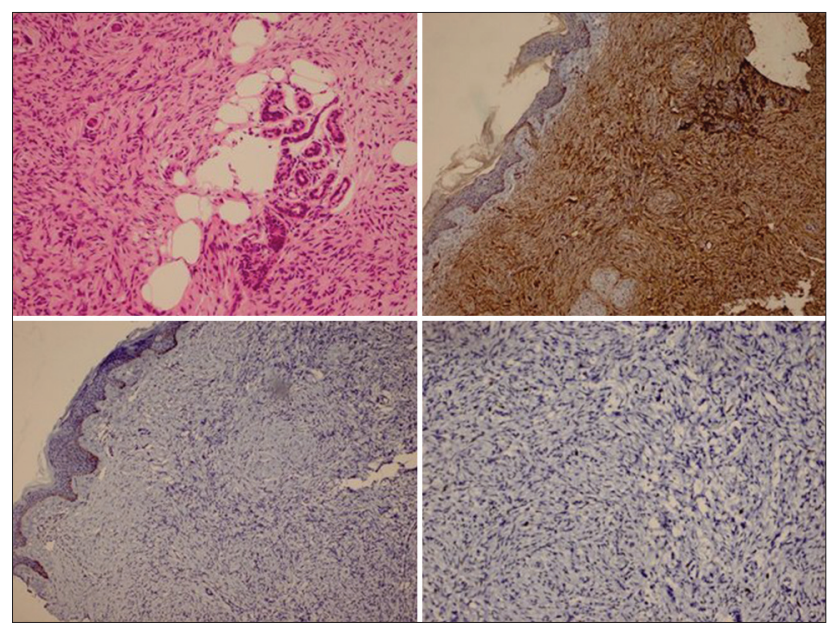

Figure 3: Histopathological features of the neoplasm demonstrating neoplastic cells infiltrating fat tissue (H\&E x40, left top). Immunohistochemistry findings; tumor cells stained positively for CD34 (right top), negatively for CD68 (left bottom), 5\% positively for Ki67 (right bottom). most of the soft tissue tumors because of the fact that it is indeed slowly progressive, locally aggresive tumor and has a high rate of recurrence rates after surgical treatment. DFSP is a rare tumor, its exact incidence is not known [1-5]. Recently it has been reported that the overall incidence of DFSP in United States is 4.1 per million person-years [6].

We present this case because of the rare reported cases of DFSP in the literature. Our patient manifested typical features of DFSP, in that her history, clinical and histopathological findings were all consisted with the characteristics of DFSP. It is known that DFSP is generally located on trunk, however lower extremities are the second most common localization for DFSP [3]. Moreover, proximal regions of the limbs are more favored [4] as in our case. DFSP usually starts with one or more small, firm, flesh-coloured or pink-red dermal nodules. Over a period of time, these nodules coalesce and the tumor turn into a indurated, hard plaque with multiple nodules or protuberances. A rapid growth phase has been described, which is the time that the tumor enters an accelerated expansion period. As the tumor enlarges, a dusky-reddish blue discoloration surrounding the lesion appears. Most of the time initially painless lesion turn out to be a painful tumor. Moreover, ulceration along with discharge have been described for DFSP [1-4].

The lesion of our case also manifests typical histopathological features of DFSP. It is known that DFSP has a distinctive histologic appearance. In DFSP, the dermis and subcutaneous tissue are replaced by bundles of uniform, spindle-shaped cells. Tumor cells infiltrate and merge into the deeper dermis forming bands, in which this histopathological entity is called as storiform pattern. Immunhistochemical studies can be helpful in making the diagnosis of DFSP. In our cse, immunohistochemically tumor cells stained positively for CD34, negatively for CD68 and 5\% positively for Ki67, which support the diagnosis of DFSP.

\section{REFERENCES}

1. Bogucki B, Neuhaus I, Hurst EA. Dermatofibrosarcoma protuberans: a review of the literature. Dermatol Surg. 2012;38:537-51.

2. Laskin WB. Dermatofibrosarcoma protuberans. CA Cancer J Clin. 1992;42:116-25.

3. Mendenhall WM, Zlotecki Ra, Scarborough MT. Dermatofibrosarcoma protuberans. Cancer. 2004;101:2503-8.

4. Calonje E. Soft-Tissue Tumours and Tumour-like Conditions. In: Burns T, Breathnach S, Cox N, Grittiths C, eds. Rook's Textbook of Dermatology. $8^{\text {th }}$ ed. Oxford: Wiley-Blackwell 2010. p.56. 12-14.

5. Bichakjian CK, Olencki T, Alam M, Andersen JS, Berg D, Bowen GM, 
www.odermatol.com

et al. Dermatofibrosarcoma protuberans, version 1.2014. J Natl Compr Canc Netw. 2014;12:863-8.

6. Kreicher KL, Kurlander DE, Gittleman HR, Barnholtz-Sloan JS, Bordeaux JS. Incidence and Survival of Primary Dermatofibrosarcoma Protuberans in the United States. Dermatol Surg. 2016;42Suppl 1:S24.
Copyright by Nuran Alli, et al. This is an open-access article distributed under the terms of the Creative Commons Attribution License, which permits unrestricted use, distribution, and reproduction in any medium, provided the original author and source are credited.

Source of Support: Nil, Conflict of Interest: None declared. 